\title{
Lebensspuren holzzerstörender Organismen an fossilen Hölzern aus dem Tertiär der Insel Lesbos, Griechenland
}

\author{
Herbert Süss $^{1}$ \& Evangelos Velitzelos ${ }^{2}$
}

Mit 2 Abbildungen und 3 Tafeln

\section{Zusammenfassung}

Lebensspuren (Schadbilder) holzzerstörender Organismen an fossilen Holzresten aus dem Untermiozän von Lesbos (Griechenland) werden beschrieben. Von pflanzlichen Holzzerstörern konnten Bakterien, imperfekte Pilze, Weiß- und Braunfäulepilze und in das Holz eingewachsene Wurzeln nachgewiesen werden. Von tierischen Holzzerstörern wurden Termitenfraß. durch Pflanzensauger (Homopteren) verursachtes Wundgewebe. Larvenfraß der Kambium-Minierfliege Palaeophyiobia (Agromyzidae. Diplera) und Fraßgänge mit Koprolithen verschiedener Käferarten (Anobiiden?) und Milben (Acari) gefunden. Außerdem werden durch Kristallisationsvorgänge im Holz verursachte kugelförmige Gebilde beschrieben.

Schliisselwörter: Lesbos, Griechenland, Untermiozän, Remincralisation, Abbauerscheinungen, Insekten, Pilze. Arthropoden.

\begin{abstract}
Traces of wood destroying organisms on fossil wood from the Lower Miocene of Lesbos (Greece) are described. Among nonanimal wood destroyers evidence is presented of bacteria, Fungi imperfecti. whiterot and brownrot fungus and penetrating roots. Animal wood destroyers include termite feeding traces, wound tissues produced by plant suckers (Homoptera), larval feeding traces of the cambium miner Palaeophytobia (Agromyzidae, Diptera) and feeding channels, with coprolites, of several beetle species (Anobiidae?) and Mites (Acari). In addition globe-like structures produced in the wood through crystallization processes are described.
\end{abstract}

Key words: Lesbos, Greece, lower Miocene, fossil wood, remineralization, degradation, insects, fungi, arthropods.

\section{Einleitung}

Für das Studium der Wechselbeziehungen zwischen Pflanzen und Tieren sowie Pflanzen untereinander innerhalb bestimmter geologischer Zeiträume nimmt die Paläoxylotomie eine besondere Rolle ein, denn Holz ist aufgrund seiner strukturellen Eigenschaften wie kein anderes Pflanzengewebe geeignet, bakterielle und pilzliche Abbauerscheinungen sowie durch Tiere verursachte Bearbeitungs- und Fraßspuren mit ihren Kotrückständen (Koprolithen) im fossilen $\mathrm{Zu}$ stand zu erhalten. Holzanatomen können daher wichtige Beiträge über die Biologie, den Wirtspflanzenkreis, die geographische Verbreitung, das geologische Alter und die Evolution der früher in und an der Pflanze gelebten Organismen liefern. Am häufigsten sind Abbauerscheinungen von holzzerstörenden Pilzen und Fraßspuren von Käfern überliefert. Aber auch andere Insekten wie Springschwänze, Termiten, Schmetterlinge. Minierfliegen, Bienen, Holzwespen und Ameisen sind fossil als Holzbewohner beziehungsweise Holzzerstörer bekannt geworden. Von Milben, Muscheln und Vögeln sind ebenfalls Lebensspuren an fossilen Holzresten nachgewiesen. Aber auch nachträglich ins Holz eingewachsene Pflanzenwurzeln wurden an fossilen Holzresten gefunden.

Unter den aus untermiozänen Schichten stammenden verkieselten Hölzern der Insel Lesbos. Griechenland, befinden sich viele Holzreste mit Schadbildern sehr verschiedener holzzerstörender Organismen. Da die damalige Vegetation

\footnotetext{
Museum für Naturkunde, Institut für Paläontologie, Invalidenstr. 43, D-10115 Berlin, Germany.

2 National University of Athens, Subfaculty of Earth Sciences, Department of Historical Geology and Palcontology, Panepistimiopolis, 15784 Athens, Greece.

Erhalten Februar 2001, angenommen Juni 2001
} 
des nordwestlizhen Teils der Ägäis durch gewaltige Vulkanaus brüche vollständig vernichtet wurde und damit auch alle an der Holzzerstörung beteiligten Organismen. erhielten wir mit vorliegenden Untersuchungen die seltene Gelegenheit. die zeitgleich nit der Vernichtung des Baumbestandes konservierten Lebensspuren zu analysieren und bestin mten Organismen zuzuordnen.

\section{Überblick über die bisher aus der Literatur bekannten Letensspuren an fossilen Hölzern}

Konidienformen von vermutlich imperfekten Pilzen (Fungi imperfecti) wurden von G. Schönfeld (1947) in eine n Laubholz aus dem Tertiär von Kolumbien. von Süss (1980a) im Wurzelholz einer Platane aus dem Untereozän der Greifswalder Oie (Deutschland) und von Březinová \& Süss (1988) im Wurzelholz einer Kiefer aus dem Miozän von Höhmen (Tschechien) nachgewiesen. Fungi imperfecti sind an der mit Moderfäule bezeichneten 'zersetzung rezenter Hölzer maßgeblich beteiligt (Grosser 1985: 429).

Die ältesten durch Basidiomyceten verursachten Holzabbau srscheinungen wurden an Hölzern aus dem Devo 1 und Perm nachgewiesen (Taylor \& Osborn 1996). Über Pilzzerstörungen an jurassischen Koniferenhölzern berichten Müller-Stoll (1936) und Süis \& Philippe (1993). Eine Weißlochfäule im Folz von Araucarioxylon aus dem Paläozoikum cer Antarktis fanden Stubbleficld \& Taylor (1986). Durch Pilze verursachte Zersetzungserscheinungen an tertiären Bernsteinhölzern konnte Conwentz. (1890) nachweisen. und E. Schönfeld (1957) fand in einem Nadelholz aus der hessischen Braunkohle ein durch Trametites Meschinelli hervorgerufenes Krankheitsbild.

Über eingewachsene Pflanzenwurzeln in tertiäre Holzreste erichten Müller-Stoll \& Mädel (1957). Daber (1953) und Březinová \& Süss (1988).

Erste Hinw ise auf holzbohrende Insekten sind aus dem Karbon (Geinitz 1855: 1 f.) überliefert. Kolbe (1888) berichtet über Insektenbohrgänge an einem ..sog. Kohlenholz" aus ciner Braunkohlengrıbe bei Senftenberg. das in der paläontologischen Sammlung des Königlichen Museums für Naturkunde zu Berlin aufbewahrt war. Er fand dort Fraßgänge drei verschiedener Käferarten und den versteinerten Puppenrest einer wahrscheinlichen Anthribide. Über Bohrlöcher von Anobien- und Holzwespenlarven in Braunkohlenresten der Mark Brandenburg berichtet Gellhorn (1893). und Jurasky (1932) be- schreibt Fraßspuren mit Koprolithen eines Nagekäfers an einem Gymnospermenholz aus der liassischen Steinkohle von Rumänien. Das Schadbild wurde den Fraßgängen zugeordnet, die der Nagekäfer Anobia striatum Oliver im Holz hinterlässt. Bohrgänge von Käfern oder Holzwespen und durch Ameisen verursachte Holzzerstörungen an einem miozänen PinusHolz aus dem Yellowstone Nationalpark (USA) beschreibt Brues (1936) [nach Andrews (1961: 13. 202) stammt das Holz aus eozänen Schichten]. Linck (1949) wies an einem DadoxylonHolz aus dem Keuper von Thüringen zwei verschiedene Formen von Bohrgängen nach, wovon die eine als Anobichnium simile benannt wurde. Bei der anderen vermutet er Fraßspuren größerer Anobiiden. Borkenkäfern oder Holzwespen (Sirex). An einem Angiospermen-Holz aus der eozänen Braunkohle von Sachsen fand E. Schönfeld (1955) Fraßspuren eines Nagekäfers, und Tufar (1968) wies Gänge von Insektenlarven in einem Holz aus Ost-Holstein nach. Über Fraßgänge und Koprolithen von Anobium sp. in einem jungtertiären Lorbeerholz aus der südlichen Frankenalb berichtet Selmeier (1984). Fraßgänge mit Koprolithen eines holzbewohnenden Käfers miozänen Alters aus dem Lettengraben in der Rhön heschreibt Müller-Stoll (1989). Die Bohrgänge des vermeintlichen Käfers und die Koprolithen sind auffallend groß und stammen wahrscheinlich von einem großen Cerambyciden. Wegen der Ähnlichkeit des Schadbildes mit dem rezenten Großen Eichenbock, Cerambyx credo, werden Fraßgänge und Koprolithen von MüllerStoll Palaeocerambichnius tertiarius genannt. Aus dem Jura von Henan werden erstmalig für China von Zhou Zhiyan \& Zhang Bole (1989) Insektenbohrgänge mit Koprolithen an einem versteinerten Protocupressinoxylon-Holz nachgewiesen.

Im englischen und nordamerikanischen Schrifttum wurde in den letzten Jahren mehrfach über das Vorkommen von Fraßspuren in karbonischen Holzresten berichtet. Diesbezüglich verweisen wir auf die Literaturzusammenstellung bei Scott \& Taylor (1983). In ihren Ausführungen über die Pflanzen-Tier-Beziehungen während des Oberkarbons unternehmen sie den Versuch, die Koprolithen anhand ihrer Größe bestimmten Tiergruppen zuzuordnen. In permischen DadoxylonHölzern aus der Wetterau haben Goth \& Wilde (1992) Fraßspuren nachgewiesen, die nach der Größe und Form der Koprolithen, gestützt auf die Untersuchungen von Scott \& Taylor (1983), Milben (Acari) oder Springschwänzen (Collembola) zugeordnet werden. 
In zahlreichen tertiären Laub- und Nadelhölzern wiesen Süss $(1979,1980 b, 1982)$ und Süss \& Müller-Stoll (1975, 1980) Markflecke nach. Im Holz rezenter Bäume werden Markflecke durch Kambium-Minierfliegen der Gattung Phytobia Lioy (Agromyzidae, Diptera) verursacht. Im Kambium der Bäume hinterlassen die Larven dieser Fliegen Fraßgänge, die durch Proliferation parenchymatischer Zellen wieder ausgefüllt werden. Durch das sekundäre Dickenwachstum gelangen dann die mit Wundgewebe ausgefüllten Fraßgänge in das Holz.

Ein fossiles Termitennest in einem Nadelholz aus dem Unterpliozän des Wienerbeckens wird von Abel (1933, 1935: 495) beschrieben und ursächlich der noch heute im Mittelmeergebiet vorkommenden Gattung Kalotermes Hagen zugeordnet. Durch Termiten zerstörte Holzreste von Staré Sedlo (Böhmen) aus der im Museum für Naturkunde zu Berlin aufbewahrten Fossiliensammlung Heinrich Cottas (Süss \& Rangnow 1984) beschreiben Schultze-Dewitz \& Süss (1988).

Bohrlöcher von Muscheln in Ligniten aus einem Braunkohlenflöz bei Köln beschreibt Schenk (1937). Zwenger (1987) fand in einem tertiären Holzrest aus dem Geschiebe des Stettiner Sandes einer Septariengrube bei Bad Freienwalde (Brandenburg) besondere Erhaltungsformen von Teredo-Bohrgängen und Selmeier (1996) berichtet über zahlreiche Teredo-Fraßgänge in einem verkieselten Gymnospermenholz aus der Oberen Kreide von La Calamine (Belgien).

Das Vorkommen von Spechtvögeln im Eozän ist durch eine Spechthöhle in einem fossilen Stammrest aus Arizona nachgewiesen (Buchholz 1986).

\section{Holzzerstörende Organismen an den fossilen Hölzern von Lesbos}

\section{Pflanzen}

Eine durch Bakterien geschädigte Holzstruktur zeigen zwei in der Nähe der Ortschaft Gavathas aufgesammelte Nadelholzgerölle (Lesbos 162, 163). Vor ihrer Fossilisierung müssen die Stücke bereits längere Zeit im Wasser gelegen haben, denn Bakterien befallen nur extrem feuchtes Holz. Durch ihre anaerobe Lebensweise können sie die parenchymatischen Zellen der Holzstrahlen weitgehend abbauen. Lignifizierte, d. h. verholzte Zellwände werden dagegen nicht angegriffen (Schmidt 1980). Auf dem Tangential- und
Radialschliff der Holzreste ist der Abbau der Holzstrahlzellen bereits weit fortgeschritten (Taf. 1: 1, 2) und das Schadbild stimmt mit dem von Grosser (1985: 89, Abb, 6.66) beschriebenen weitgehend überein. Wenn durch den bakteriellen Abbau der Holzstrahlzellwände die Kreuzungsfeldtüpfel und das Fehlen oder Vorhandensein der Abietineen-Tüpfelung nicht nachgewiesen werden kann, ist die genaue Bestimmung eines Holzes nicht möglich.

Im Holz eines Baumstammes von Tetraclinoxylon velitzelosi Süss (1997) aus Pali Alonia (Lesbos 145) wurden in einem Tangentialschliff Reste von Pilzhyphen gefunden, wovon eine $\mathrm{Hy}-$ phe mit einem Durchmesser von $10-12 \mu \mathrm{m}$ in tangentialer Richtung fünf Tracheiden und einen Holzstrahl überquert. Bei der Überwindung der Tracheidenwände wird der Weg durch die Hoftüpfel, wobei sich die Hyphe stark verdünnt, bevorzugt. Der Holzstrahl wird durch Auflösen der Mittellamelle zwischen zwei übereinander liegenden Zellen überquert (Taf. 1: 3). Diese Hyphen sind den von Felix (1894: Taf. 19: 5, 6) zu den Hyphomyceteae (imperfekte Pilze) gestellten und als Haplographites cateniger beschriebenen und von G. Schönfeld (1947: Textabb. 21) bei $S_{a-}$ pindoxylon antioquiense Kräusel \& Schönfeld gefundenen sehr ähnlich. Da die Tracheidenwände von dem Pilz nicht merklich abgebaut wurden, nehmen wir an, dass die Hyphen ebenfalls den Fungi imperfecti, die lignifiziertes Zellwandmaterial nicht angreifen, zugeordnet werden können.

Mehrere Fundstücke des versteinerten Waldes von Lesbos zeigen charakteristische Holzzerstörungen, die nur durch die Einwirkung parasitischer Pilze entstanden sein können. In ihren Schadbildern stimmen sie weitgehend mit Holzzerstörungen überein, die auch parasitische Basidiomyceten an jetztzeitigen Nadelgehölzen verursachen. Vor allem wegen der großen Übereinstimmung mit dem Schadbild, das Trametes pini Thore ex Fr. [= Phellinus pini (Thore ex Fr.) Fr.] an rezenten Pinus-Arten verursacht. wurde für eine derartige Holzzerstörung an fossilen Gymnospermen die Formgattung Trametites Mesch eingeführt (Müller-Stoll 1951: 750). Phellinus pini, der Kiefernbaumschwamm, verursacht durch den sukzessiven Abbau des Lignins und der Zellulose eine besondere Form der Korrosionsfäule, die Weißlochfäule. Dabei entstehen durch den lokal verschieden intensiven Ligninabbau viele kleine, mehr oder weniger gleichmäßig im Holz verteilte längliche Löcher (Grosser 1985: 42). An Holzfunden aus Lesbos, über die wir bereits schon früher berichteten (Süss \& Ve- 

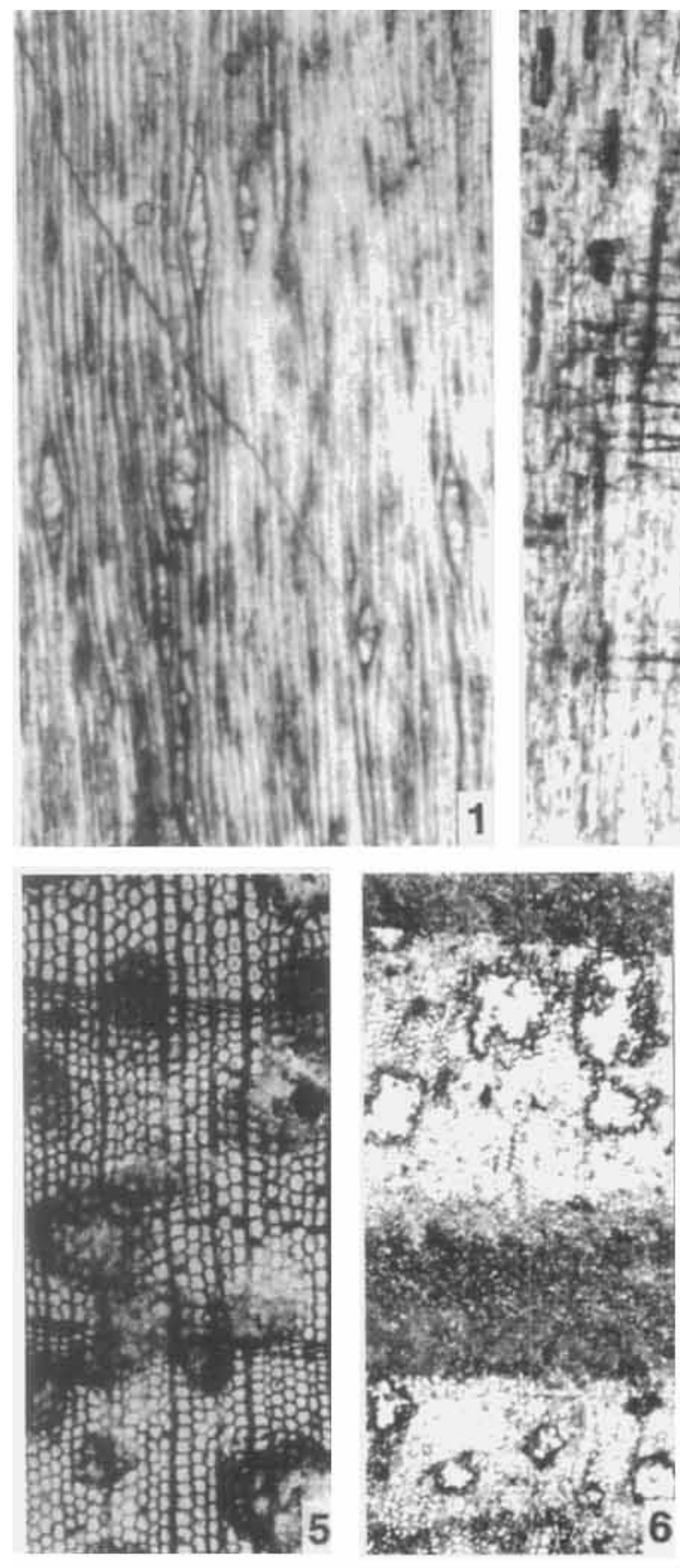
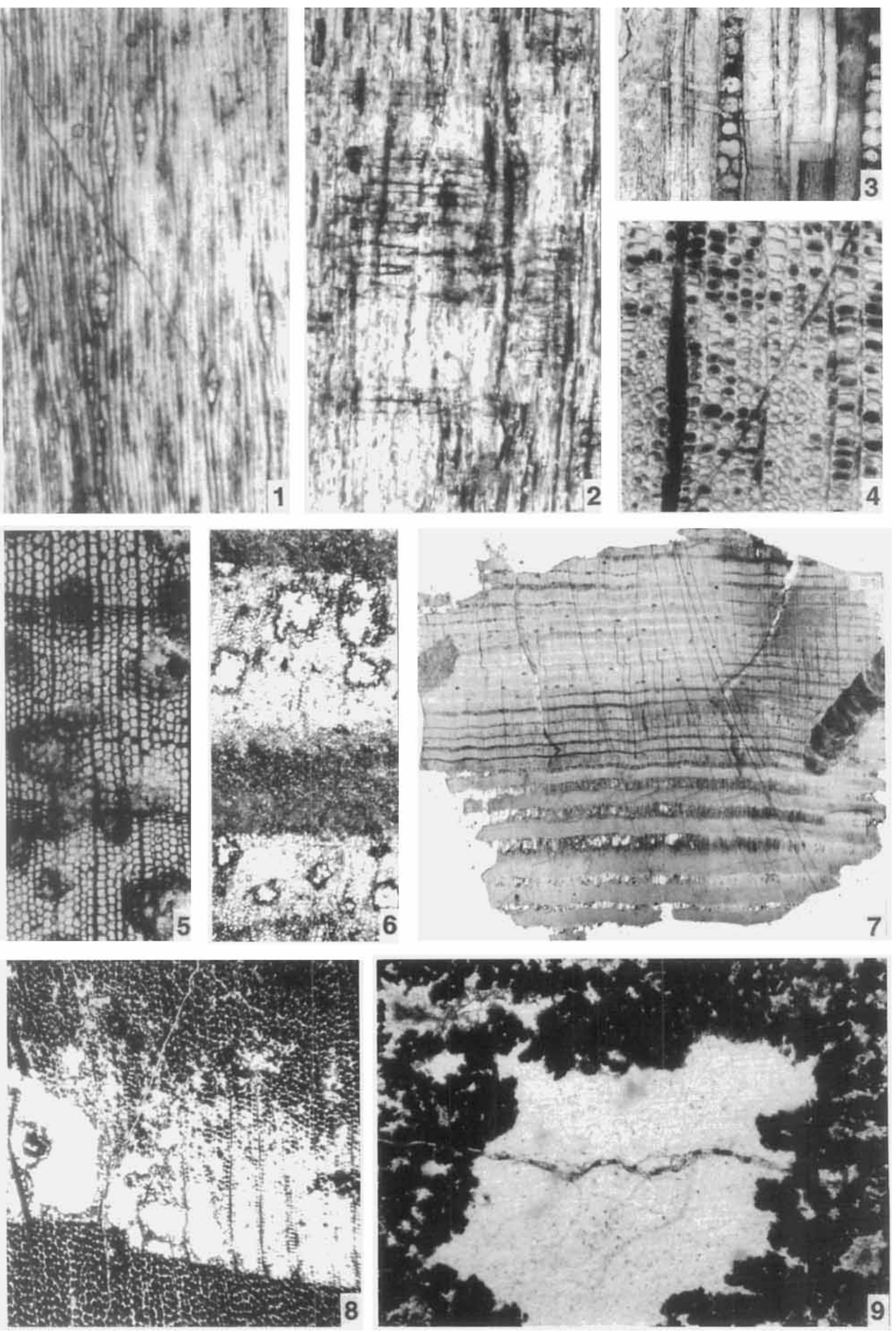
litzelos 1997), konnten wir nahezu alle Stadien dieses Schadbildes nachweisen. So sind auf dem Querschnitt eines Fundstückes von Taxodioxylon albertense (Penhallow) Shimakura (Lesbos 118) zahlreiche, leicht verfärbte, nesterförmige Zersetzungserscheinungen vorhanden, von deren Zentrum aus eine nach außen fortschreitende Gewebeauflösung beobachtet werden kann (Taf. 1: 5). Im Holz von Glyptostroboxylon microtracheidale Süss \& Velitzelos (Lesbos 141) ist die Holzzerstörung so weit fortgeschritten, dass bereits gewebefreie, lochförmige Hohlräume entstanden sind (Taf. 1: 6).

Eine durch Trametites verursachte Weißlochfäule zeigt ein Holzrest (Lesbos 164) mit Piceoxylon-Struktur, bei dem die Gewebepartien des Spätholzes an einigen Stellen nahezu vollständig abgebaut sind. Auf dem Quer- und Radialschliff (Taf. 1: 7, Taf. 2: 5, 6) ist zu erkennen, dass der Pilz die unverholzten Zellwände der Holzstrahlen nicht angreifen kann, denn die in radialer Richtung verlaufenden Holzstrahlen überqueren unzerstört die nahezu vollständig aufgelösten Gewebepartien des Spätholzes. Auf dem Radialschliff sind in Längsrichtung des Holzes verlaufende längliche Gewebelücken vorhanden (Taf. 2: 5, 6), wie sie im Kernholz rezenter Nadel- und Laubbäume durch Phellinus pini erzeugt werden (Grosser 1985: 42). In diesem Holz sind außerdem noch Bohrgänge von Käferlarven vorhanden (Taf. 1: 7; Taf. 2: 5).

Eine andere Form der Holzzersetzung, die Braun- oder Destruktionsfäule, wird durch Pilze hervorgerufen, die vorwiegend Zellulose abbauen. Das zurückbleibende Lignin verursacht eine Braunfärbung des Holzes. Diese Pilze kommen vorwiegend saprophytisch an Nadelhölzern vor. $\mathrm{Zu}$ ihnen gehören die gefährlichsten Holzzerstörer des Bau- und Werkholzes wie der Echte Hausschwamm, der Kellerschwamm und der Weiße Porenschwamm (Grosser 1985: 40). Dieses Bild der Holzzersetzung zeigt ein nicht näher bestimmbarer Holzrest (Lesbos 165) mit Pinuxylon- oder Piceoxylon-Struktur. Neben einer WeiBfäule im Frühholz sind hier die Spätholzbereiche durch einen Braunfäulepilz bereits so stark abgebaut, dass die einzelnen Holzzellen nur noch als dunkelbraune amorphe Masse zu erkennen sind, und das Zellgefüge durch zahlreiche kleine Risse, Spalten und Hohlräume verloren geht. Im Endstadium lassen nur noch einzelne Gewebetrümmer den organischen Ursprung des fossilen Restes erahnen (Taf. 1: 8 ,9). Pilzhyphen von $10-15 \mu \mathrm{m}$ Breite, die anscheinend mit diesen Zersetzungserscheinungen nicht in Verbindung stehen, durch- und überqueren das zerstörte Gewebe, in einem Fall sogar einen völlig zerstörten vertikalen Harzgang (Taf. 1: 9). Diese Hyphen werden aber auch an unzerstörten Holzstellen gefunden, wo sie, ähnlich wie im Holz von Tetraclinoxylon velitzelosi (siehe oben), die Tracheiden überqueren, ohne dass ein Zellwandabbau festgestellt werden kann (Taf. 1: 4). Mit großer Wahrscheinlichkeit gehören diese Hyphen zu imperfekten Pilzen. Dieses Holz wurde demnach vor der Fossilisation von drei verschiedenen Pilzarten besiedelt: Einem Weiß- und einem Braunfäulepilz sowie von Pilzen aus der Gruppe der Fungi imperfecti.

In vier bei Eressos aufgesammelten Koniferenhölzern (Lesbos 166, 167a,b,c), darunter ein Holz mit vermutlicher Piceoxylon-Struktur und

Tafel 1. 1. Nadelholz (Lesbos 162), Tangentialschliff, bakteriell abgebaute Holzstrahlzellen, 30:1. 2. Nadelholz (Lesbos 163), Radialschliff, bakteriell abgebaute Holzstrahlzellen, 75:1. 3. Tetraclinoxylon velitzelosi Süss (Lesbos 145), Tangentialschliff, Hyphen von imperfekten Pilzen überqueren Tracheiden und einen Holzstrahl, 200:1. 4. Nadelholz (Lesbos 165), Querschliff. Hyphe eines imperfekten Pilzes überquert Tracheiden des Spätholzes, 125:1. 5. Taxodioxylon albertense (Penhallow) Shimakura (Lesbos 118), Querschliff, frühe Stadien der Weißlochfäule, 30:1. 6. Glyptostroboxylon microtracheidale Süss \& Velitzelos (Lesbos 141), Tangentialschliff, fortgeschrittene Stadien der Weißlochfäule, 30:1. 7. Piceoxylon sp. (Lesbos 164). Querschliff. durch Weißlochfäule nahezu völlig abgebaute Gewebepartien des Spätholzes (unten im Bild) und zwei Fraßgänge von Käferlarven, 4:1. (Foto: Harre). 8. Nadelholz (Lesbos 165), Querschliff, durch Weiß- und Braunfäulepilze nahezu völlig zerslörtes Holzgewebe und die Hyphe eines imperfekten Pilzes, 30:1. 9. Nadelholz (Lesbos 165), Querschliff, Hyphe eines imperfekten Pilzes überquert einen durch Braunfäulepilze völlig zerstörten vertikalen Harzgang, 75:1.

Plate 1. 1. Softwood (Lesbos 162), tangential section, wood ray cells destroyed by bacteria, 30:1. 2. Softwood (Lesbos 163), radial section, wood ray cells destroyed by bacteria, 75:1. 3. Tetraclinoxylon velitzelosi Süss (Lesbos 145), tangential section. hyphae of Fungi imperfecti cross tracheids and a wood ray, 200:1. 4. Softwood (Lesbos 165), transverse section, hyphae of Fungi imperfecti cross tracheids of latewood, 125:1. 5. Taxodioxylon albertense (Penhallow) Shimakura (Lesbos 118). transverse section, early stages of whitehole rot, 30:1. 6. Glyptostroboxylon microtracheidale Süss \& Velitzelosi (Lesbos 141), transverse section, advanced stages of whitehole rot. 30:1. 7. Piceoxylon sp. (Lesbos 164)), transverse section, tissues of lateword (below at the figure) nearly completely destroyed by whitehole rot and two feeding traces made by beetle larvae, 4:1 (Foto: Harre). 8. Softwood (Lesbos 165 ), transverse section of wood tissues nearly completely destroyed by white rot and brown rot, and hyphae of Fungi imperfecti, 30:1. 9. Softwood (Lesbos 165), transverse section, hyphae of Fungi imperfecti cross a resin canal completely destroyed by brown rot, $75: 1$. 

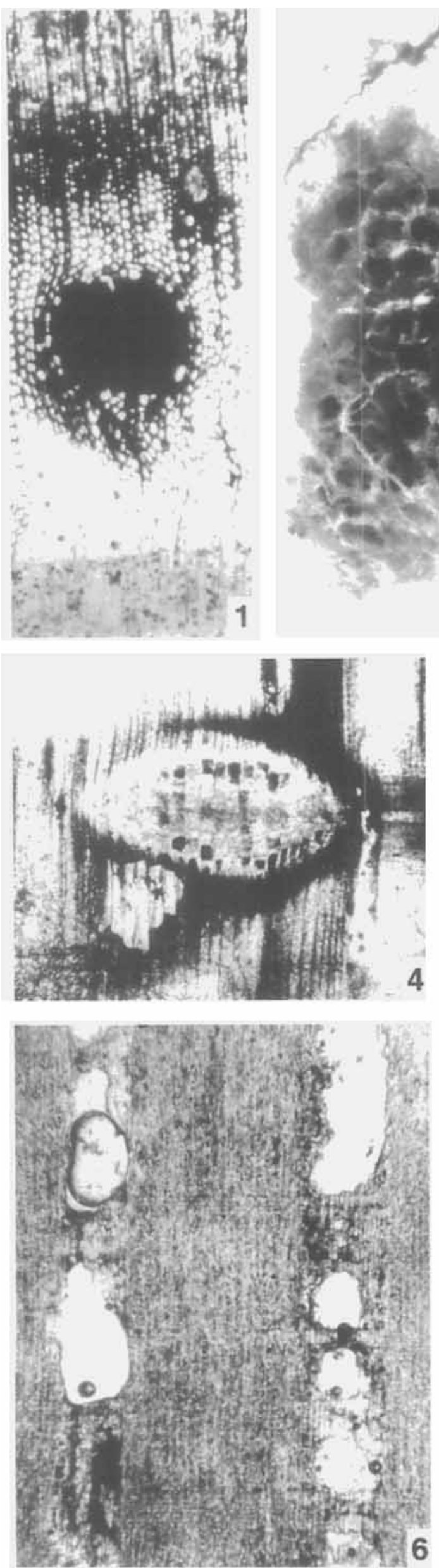
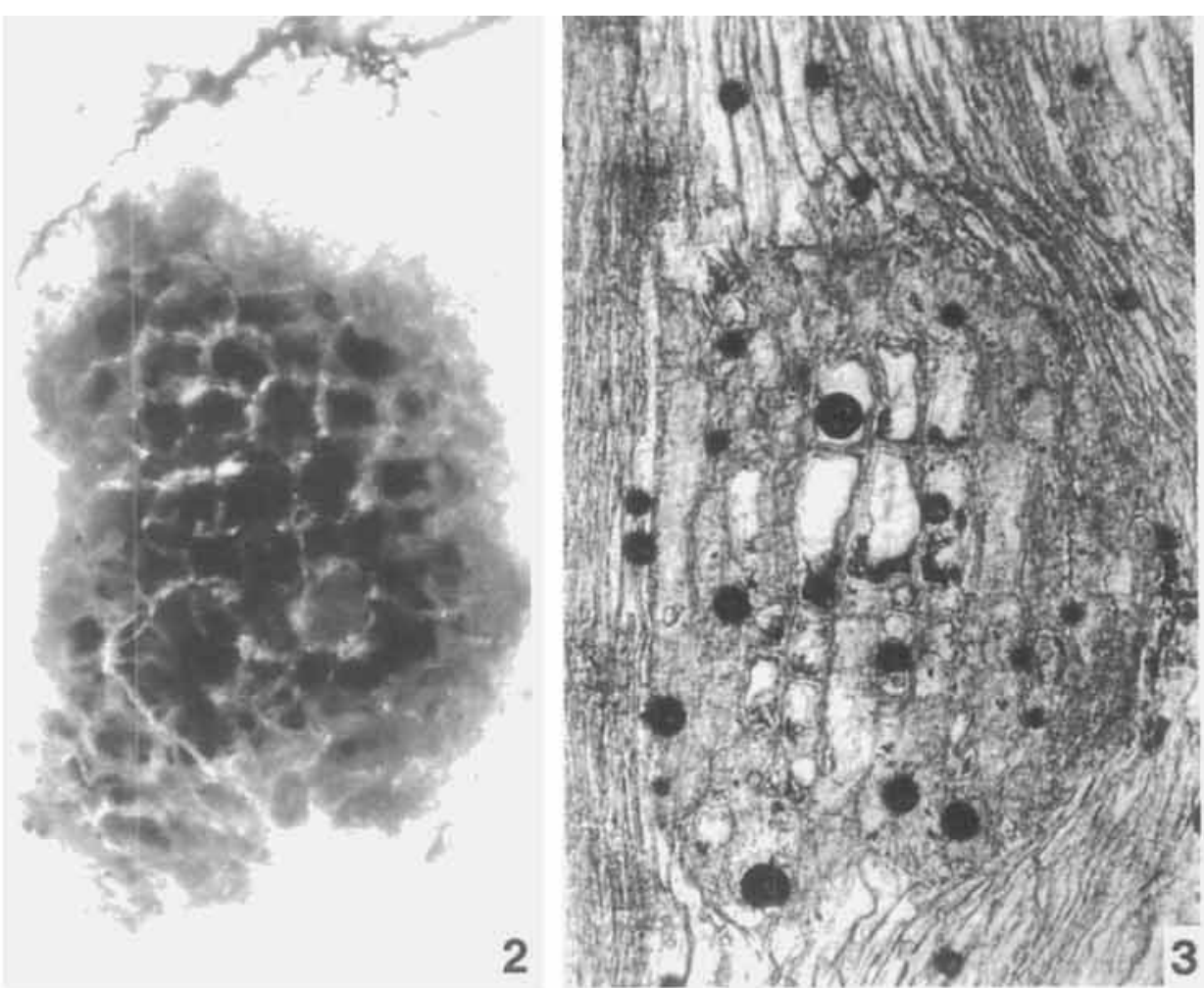
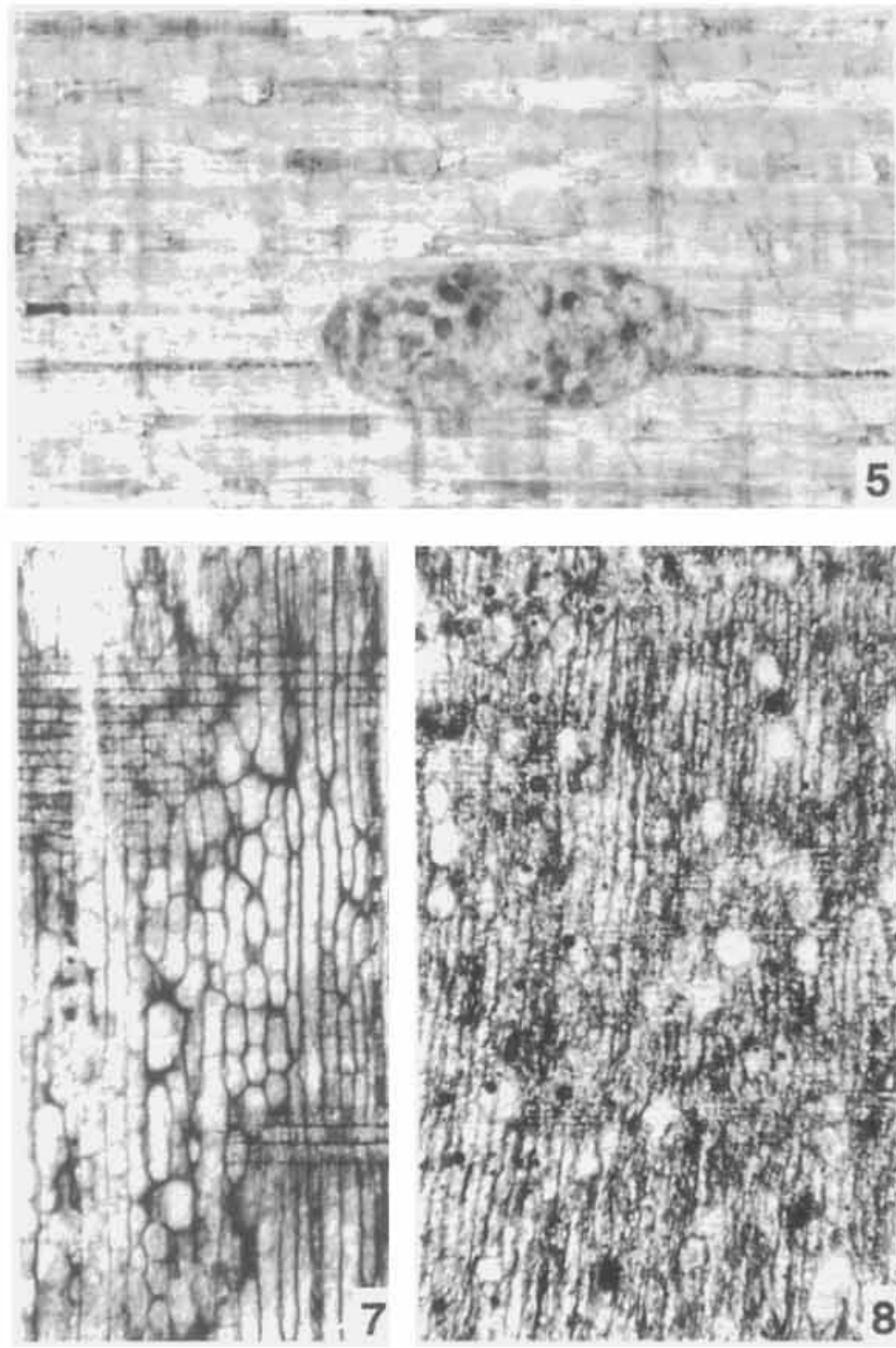

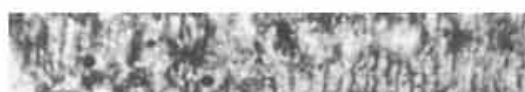

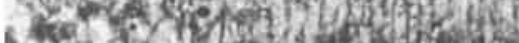

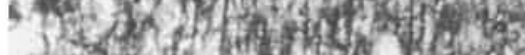

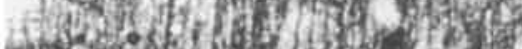
3)

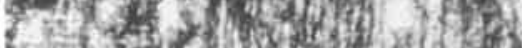

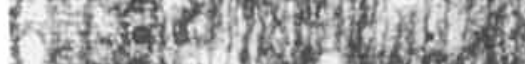
3. Sua

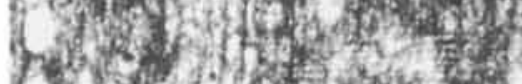
Jo 0 .

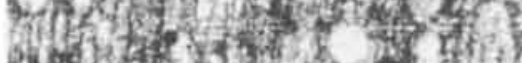

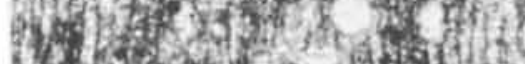

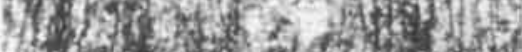
ind

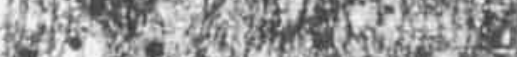

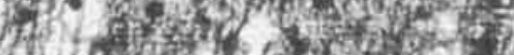

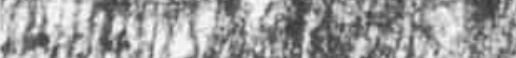

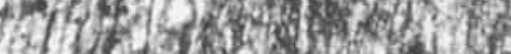

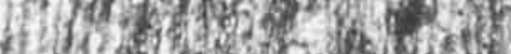

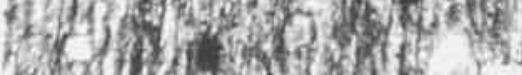
2) 1 2. 
drei zu Pinoxylon paradoxum Süss \& Velitzelos gehörende Stücke (alle drei, nach ihrem Erhaltungszustand zu urteilen, Stammreste ein und desselben Baumes), konnten zahlreiche in das Holz eingewachsene winzige Wurzeln nachgewiesen werden. Auf dem Querschliff verrät sich dies durch einen kreisförmigen Wurzeleinwuchs (Taf. 2: 1), um den herum das anliegende Gewebe durch die zunehmende Wurzelverdickung seitlich verdrängt wird. Durch Käferfraß verursachte Bohrlöcher zeigen diese Erscheinung nicht. Die Würzelchen sind oft nicht mehr erhalten oder nur durch ihre stark dunkelbraun bis schwarz gefärbten Zellen zu erkennen (Taf. 2: 1,2). Auf den Längsschnitten sind gut erhaltene Teile der längsverlaufenden Wurzeln gelegentlich oberflächlich angeschnitten. Durch ihre mehr oder weniger ovate Form und die Ausmaße ihrer Zellen heben sie sich deutlich von dem sie umgebenden Holzgewebe $a b$ und mit zunehmendem Wurzelumfang werden die Holzzellen auch hier seitlich verdrängt (Taf. 2: 3, 4). Diese Wurzeleinwüchse zeigen, dass sich diese Hölzer vor der Fossilisierung in stark erweichtem Zustand befanden. In einem natürlichen Waldbestand ist das Einwachsen von Pflanzenkeimlingen in vermorschten Stubben und Stammholzresten keine Seltenheit.

\section{Tiere}

Ein durch Insektenfraß stark geschädigter Holzrest unbestimmter Artzugehörigkeit befindet sich in der Sammlung des Naturhistorischen $\mathrm{Mu}-$ seums „Versteinerter Wald von Lesbos". Das etwa $15 \mathrm{~cm}$ breite, $15 \mathrm{~cm}$ hohe und ca. $10 \mathrm{~cm}$ dicke Stück (Abb. 1) zeigt ein Fraßbild, das in

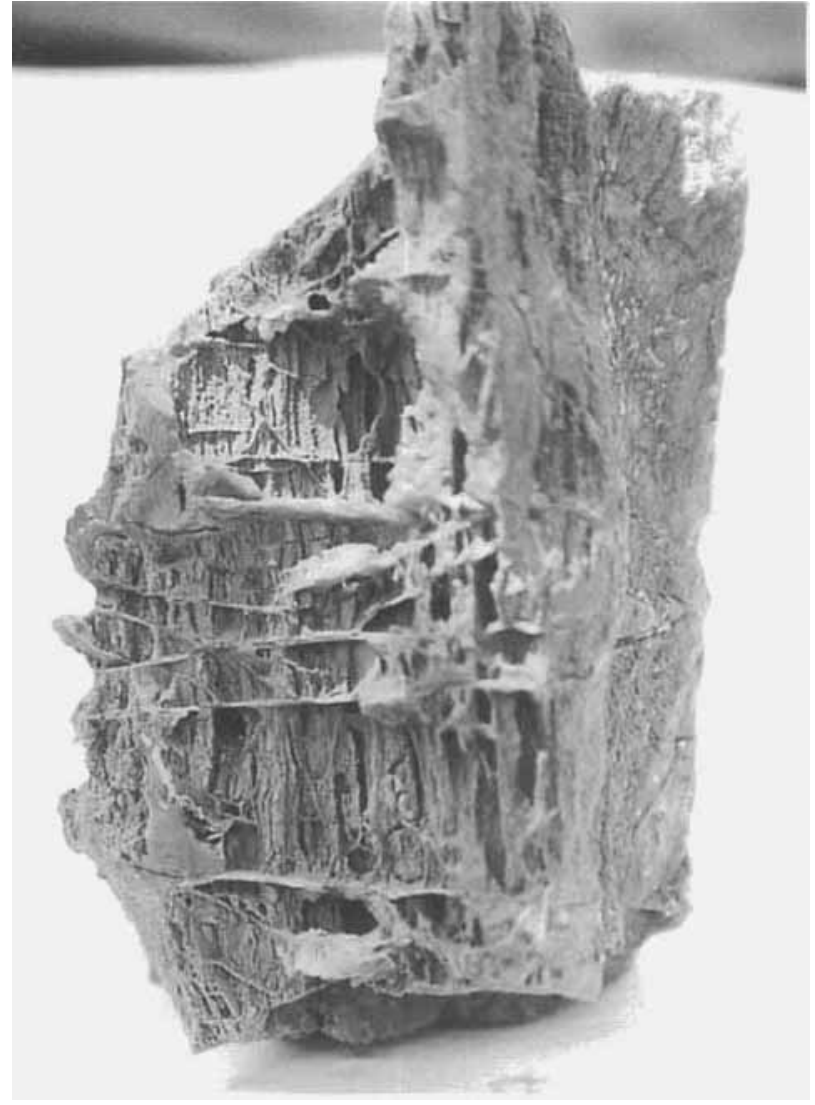

Abb. 1. Von Termiten zerstörter Holzrest aus der Sammlung des Naturhistorischen Museums .,Versteinerter Wald von Lesbos". (Foto: Böckenkamp).

Fig. 1. Termite damaged fossil wood from the collection of the Natural History Museum "Petrified Forest of Lesbos". (Foto: Böckenkamp).

seiner Gesamterscheinung auf einen Angriff von Termiten zurückzuführen ist. Als volle Holzverwerter lassen Termiten nur statisch wichtige Brücken ihres "Wohngebäudes" stehen. Das ligninreiche Spätholzgewebe wird dabei zwangsläufig mitgefressen. Holzbewohnende Ameisen lassen dagegen fast immer hartes Spätholz

Tafel 2. 1. Nadelholz (Lesbos 166), Querschliff, durch Wurzeleinwuchs verursachte Holzzerstörung. 30:1. 2. Nadelholz (Lesbos 167). Querschliff, Zcllen einer in das Holz eingewachsenen Wurzel, 75:1. 3. Radialschliff (Lesbos 167), oberflächlich angeschnittene Zellen ciner in axialer Richtung des Holzgewebes eingewachsenen Wurzel; Gewebe des Frühholzes seitlich verdrängt, 75:1. 4. Nadelholz (Lesbos 166), Radiaischliff, oberflächlich angeschnittene Zellen einer in axialer Richtung des Holzgewebes cingewachsenen Wurzel, 30:1. 5. Nadelholz. (Lesbos 164). Radialschliff. mehr oder weniger gleichmäßig im Holz verteilte Löcher einer Weißlochfäule und ein angeschnittener Fraßgang einer Käferlarve, 7,5:1 (Foto: Harre). 6. Nadelhols. (Lesbos 164). Radialschliff, fortgeschrittenes Stadium einer Weiblochfäule, 30:1. 7. Glyptostroboxylon microtrachcidale Süss \& Velitzelos (Lesbos 141). Radialschliff, Wundgewebe mit anormal ausgebildeten Frühholztracheiden. 30:1. 8. Pinltiry/on sp. (Lesbos 168), Radialschliff, durch Kristallisationsvorgänge entstandene, schrotschussartig verteilte kugelförmige Gebilde, 30:1. Plate 2. 1. Softwood (Lesbos 166), transverse section of wood penetrated by a root causing wood destruction, 30:1. 2. Softwood (Lesbos 167), transverse section, cells of a root penetrating wood, 75:1. 3. Softwood (Lesbos 167). radial section. superficial slice of cells of a root penetrating wood in axial direction; tissue of early wood lateral crowded out. 75:1, 4. Softwood (Lesbos 166), radial section, superficial slice of cells of a root penetrating wood in axial direction, 30:1. 5. Softwood (Lesbos 164), radial section, more or less evenly distributed holes of withehole rot and a fecding trace of a beetle larva. 7,5:1 (Foto: Harre). 6. Softwood (Lesbos 164), radial section, advanced stage of whitehole rot, 30:1. 7. Glyptostroboxylon microtracheidale Süss \& Velitzelos (Lesbos 141), radial section, wound tissue with anomalously developed tracheids of early wood. 30:1. 8. Pinuxylon sp. (Lesbos 168), radial section, shotlike distribution of globelike structures caused by processes of crystallisation. 30:1. 
unberührt (Schultze-Dewitz. schriftliche Mitteilung). Bei unsırem Stück kann durch die teilweise gut erhalte le Auskleidung der Fraßkammern mit einem Gemisch aus Kot. Sand und humosen Bestandteilen auf den Angriff von Erdtermiten oder so genannten Feuchttermiten geschlossen werden. Trockentermiten zeigen nicht diese Erscheinung. Dis Fossilisierung dieser Auskleidung ist wegen des Fehlens eines organischen Skeletts sehr locker und mit einem Sediment vergleichbar. das sich relativ leicht abstoßen lässt. an unserem Stück an einigen Stellen jedoch noch gut erhalten ist ( $A$ bbb. 1). Im Tertiär von Europa ist die Insektenordnung Isoptera mit mehreren Gattungen durch Imagines seit dem Eozän nachgewiesen. Im urteren Miozän ist ihr Vorkommen mit Arten der Gattungen Mastotermes Froggalt. Miotermes Rcsen, Macrotermes Holmgren und Ulmeriella Mc unier belegt (Schultze-Dewitz \& Süss 1988). Rezent kommen im Mittelmeergebiet die Arten Kc lotermes flavicollis Fabrizius und Reticulitermes lucifugus Rossi vor. Beide Arten bauen ihre Nester im toten Holz alter Baumstämme (Rammer 1952: 233).

Süss \& Veli zelos (1997) fanden an den Holzrest von Gyptostroboxylon microtracheidale (Lesbos 141) außer der Weißlochfäule (siehe oben) an melireren Stellen des Radialschliffes Wundgewebetildungen. die aus zahlreichen unterschiedlich lingen $(75-270)(\mathrm{m})$. gekammerten Tracheiden bustanden (Taf. 2: 7). Dieses abnorme Gewebe beginnt stets im ersten Frühholz und geht in radialer Richtung nach 8-15 Tracheidenreihen wieder in normales Holzgewebe über. In axiale $\mathrm{r}$ Richtung ist es in den einzelnen Zuwachszoner unterschiedlich weit ausgedehnt. In einigen Zuwachszonen fehlt es jedoch völlig. Wundgewebe $\mathrm{m}$ Holz kann entweder durch mechanische oder tierische Einwirkung auf den noch lebenden Baum entstehen. Nach unserer Meinung kann dieses Wundgewebe nur durch parasitisch letiende Ticre entstanden sein. die gleich zu Besinn dor Vegetationsperiode die Kambiumzone verletzten. Liphschitz \& Mendel (1987) berich1en von derartigen Verletzungen. die das Insekt Matsucoccus josephi Bodenheimer \& Harpaz, eine Homoptere (Pflanzensauger) aus der Familie Margarodidae. am Holz von Pinus halepensis Miler verursacht. Auf die Attacke dieses Insekts reagiert die Kambiumzone ebenfalls mit der 3ildung eines Wundgewebes, welches dem von uns beobachteten sehr ähnlich ist. Es ist deshalb nicht auszuschließen. dass für die Kambiumreak ionen. wic sie in unserer Holzprobe vorliegen. eventuell ebenfalls Insekten aus der Ordnung Homoptera verantwortlich zu machen sind. In den Schliffen eines zerstreutporigen Laubholzes aus dem Areal des versteinerten Waldes von Lesbos waren zahlreiche Markflecke (pith flecks) vorhanden, die an heutigen Bäumen durch Kambium-Minierfliegen der Gattung Phytobia aus der Dipteren-Familie Agromyzidae verursacht werden (siehe S. 59). Die Gattung Phytobia ist seit dem Eozän sowohl durch Imagines als auch durch das Fraßbild bekannt (Süss \& Müller-Stoll 1980, Spencer 1990: 390). Für das Fraßbild der Kambium-Minierfliegen an fossilen Angiospermenhölzern wurde von Süss \& MüllerStoll (1975) der Gattungsname Palaeophytobia eingeführt. Für cine Mikrofotografie standen uns dic Schliffe leider nicht zur Verfügung.

Von einem Holzfossil (Lesbos 169), das als loses Stück bei Chamandrula aufgesammelt wurde, liegen uns drei Schliffe (Quer-, Tangential- und Radialschliff) vor, an denen zahlreiche Fraßgänge und Koprolithen von Arthropodenlarven nachgewiesen werden konnten. Wegen seiner holzanatomischen Merkmale wurde der Holzrest zu Pinorylon pseudoparadoxum Süss \& Velitzelos gestellt. Die Fraßgänge dieses Holzzerstörers verlaufen vorwiegend in Längsrichtung des Holzes. wobei sich die Gänge häufig verzweigen und flächenartig verbreitern können. Die Stärke des Befalls kann am besten am Querschliff demonstriert werden. Auf einer Fläche von $24 \times 36 \mathrm{~mm}$ (Abb. 2) sind 48 meist vertikal verlaufende Fraßgänge angeschnitten. Mitunter verlaufen die Gänge aber auch auf kurzer Distanz in horizontaler Richtung, wobei sie die Zuwachszonengrenzen überqueren. Die Käferlarven haben dann sowohl Zellen der Früh- als auch der Spätholzbereiche zerstört (Taf. 3: 1-3). Auf der Tangentialansicht des Holzes wird deutlich, dass die holzzerstörenden Larven die weicheren Zellen des Frühholzes als Fraßmaterial bevorzugten. Einzelne Gänge von ca. $0,5 \mathrm{~mm}$ Breite laufen häufig zu großflächigen Fraßstellen zusammen und bilden dann einen Platzfraß, der nicht selten eine Breite von ca. $5 \mathrm{~mm}$ erreichen kann (Taf. 3: 5). Die Bohrgänge sind häufig mit kleinen spanförmigen. bis $5 \mu \mathrm{m}$ langen und $2,5 \mu \mathrm{m}$ breiten ungefressenen Fraßrückständen ausgefuillt. Auf dem Radialschliff sind in vertikal verlaufenden Fraßgängen drei verschieden große, lang-elliptische bis walzenförmige und runde Koprolithen vorhanden. Die großen walzenförmigen sind $250 \mu \mathrm{m}$ im Durchmesser und bis $1000 \mu \mathrm{m}$ lang (Taf. 3: 4, 5), die mittelgroßen langelliptischen sind $70 \mu \mathrm{m}$ im Durchmesser und $120 \mu \mathrm{m}$ lang (Taf, 3: 7), und die kleinen runden haben einen 


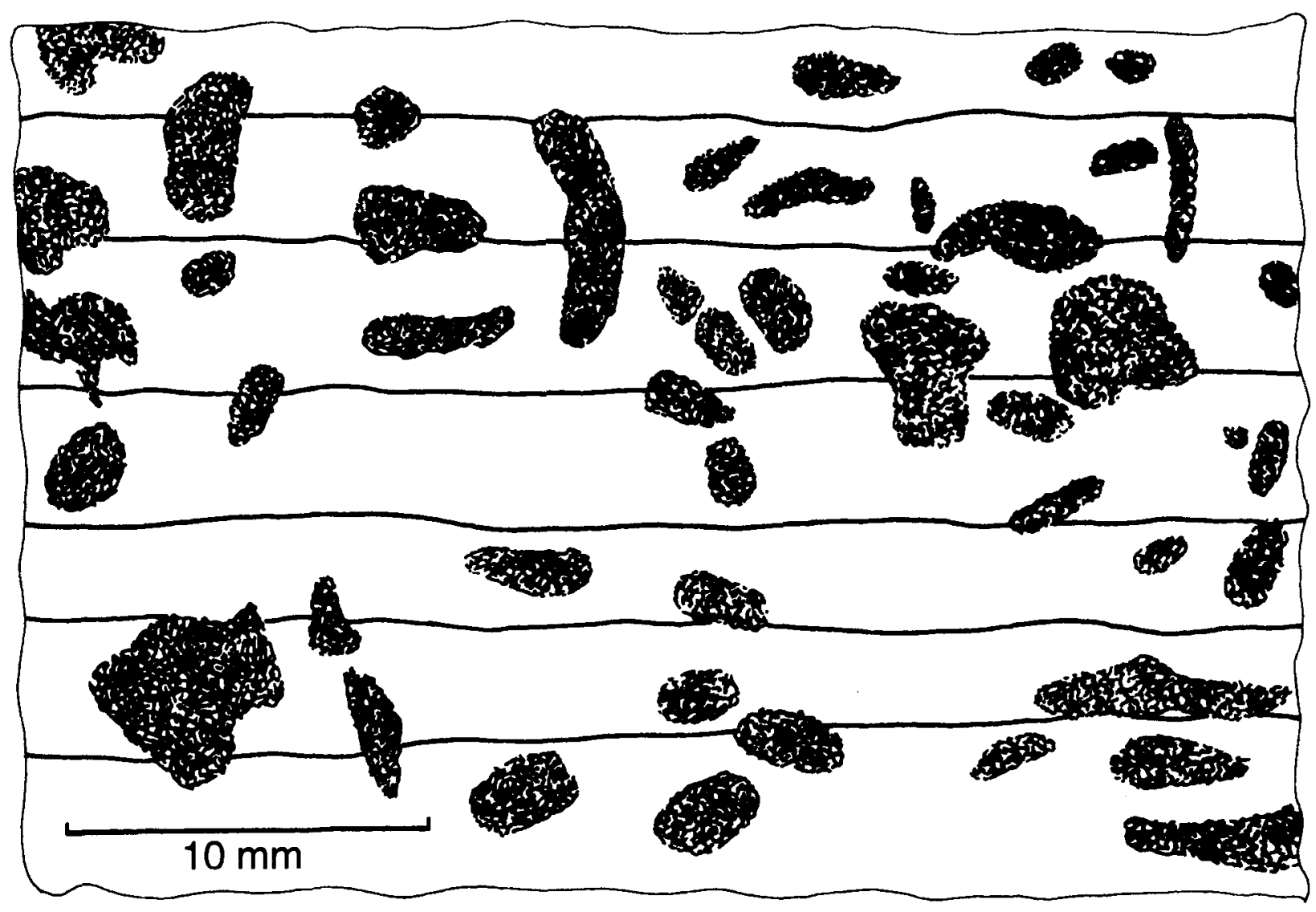

Abb. 2. Pinoxylon pseudoparadoxyum Süss \& Velitzelos (Lesbos 169), Querschnittsbild, zahlreiche Fraßgänge von Anobiiden mit Koprolithen und Fraßrückständen (etwas schematisiert).

Fig. 2. Pinoxylon pseudoparadoxum Süss \& Velitzelos (Lesbos 169), cross-section, numerous feeding traces with coprolites and feeding remains produced by a species of Anobiidae (slightly schematized).

Durchmesser von 25-40 um (Taf. 3: 6, 8). Die Fraßgänge mit den großen und mittelgroßen Koprolithen sind stets mit kleinen spanartigen Fraßrückständen ausgefüllt, die regellos in den Gängen verteilt sind. In den mit kleinen Koprolithen besetzten Gängen sind keine Fraßrückstände vorhanden. Als Verursacher dieses Schadbildes kommen wohl hauptsächlich Coleoptera-Arten in Frage. Selmeier (1984), der in einem jungtertiären Lorbeerholz ebenfalls Koprolithen in drei verschiedenen Größen fand, macht für das Schadbild Larven von Anobiiden verantwortlich. Die im vorliegenden Holzrest gefundenen groBen Koprolithen fallen in die Variationsbreite der von ihm angegebenen großen bis mittelgroBen Koprolithen. Becker (1949) und Müller-Stoll (1989) geben die Größe der Koprolithen von Anobium punctatum De Geer mit 400-800 $\mu \mathrm{m}$ bzw. 200-450 um an. Auch diese Angaben entsprechen den großen Koprolithen des Holzes von Chamandrula. Die Annahme ist deshalb berechtigt, dass die großen Koprolithen mit einem mittleren Durchmesser von $250 \mu \mathrm{m}$ und einer Länge bis $1000 \mu \mathrm{m}$ ebenfalls von Anobium-Lar- ven stammen. Dagegen müssten nach den Angaben von Scott \& Taylor (1983) die mittelgroßen $(70-120 \mu \mathrm{m})$ und die kleinen $(25-40 \mu \mathrm{m})$ von Springschwänzen (Collembola) oder Milben (Acari) hinterlassen worden sein. Müller-Stoll (1989) weist jedoch darauf hin, dass verschieden alte Stadien von Käferlarven auch verschieden große Bohrgänge und Koprolithen hinterlassen, und nur wenn keine Übergänge in ihrer Größe vorhanden sind, verschiedene Verursacher vermutet werden können. Aus dieser Sicht ist anzunehmen, dass die großen und mittelgroßen Koprolithen im Holzrest von Chamandrula das Ergebnis verschieden alter Larvenstadien von Anobiiden sind. Gestützt wird diese Annahme durch die Tatsache, dass sowohl in den breiten als auch in den schmalen Gängen Fraßrückstände vorhanden sind (Taf. 3: 4, 5, 7). Die Gänge, die die kleinen Koprolithen (nur 25-40 $\mu \mathrm{m}$ im Durchmesser) enthalten, sind dagegen mit einer Breite von $0,2-0,3 \mathrm{~mm}$ bedeutend enger als die Gänge mit den großen bzw. mittelgroßen Koprolithen, Fraßrückstände sind nicht vorhanden (Taf. 3: 6, 8). Dieses Schadbild könnte demnach 

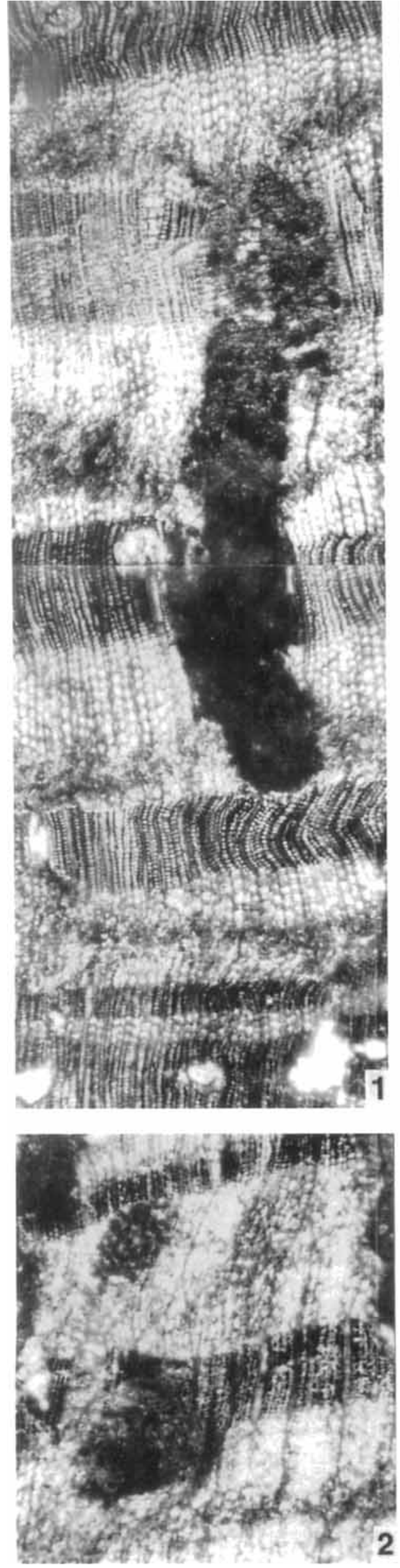
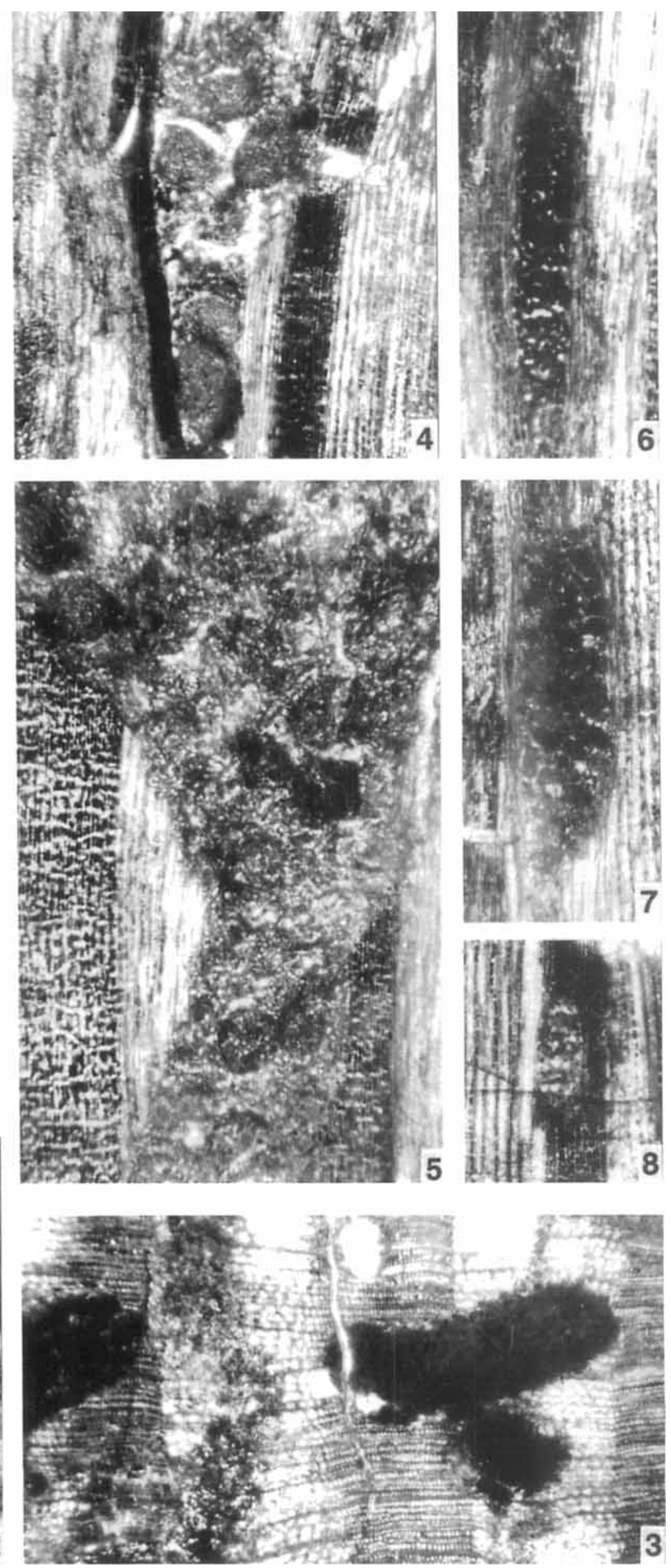
von Milben (Acari) verursacht sein. Von ihnen ist zwar bekannt, dass sie vorwiegend von abgestorbenem Pflanzenmaterial leben, einige Arten aber auch im Holz bohren können (Luxton 1972, Scott \& Taylor 1983). An der Zerstörung des Holzrestes von Chamandrula waren demnach mindestens zwei verschiedene Tierarten beteiligt:

1. Käferlarven aus der Familie Anobiidae mit Fraßgängen von $0,5 \mathrm{~mm}$ Breite und großen platzartigen Erweiterungen, die mit bis $5 \mu \mathrm{m}$ langen und 2,5 $\mu \mathrm{m}$ breiten, spanartigen Fraßrückständen und langelliptischen bis walzenförmigen Koprolithen von zwei verschiedenen Größen $(70 \times 120 \mu \mathrm{m}$ und $250 \times 1000 \mu \mathrm{m})$ ausgefüllt sind.

2. Milben (Acari) mit Fraßgängen von $0,2-0,3 \mathrm{~mm}$ Breite und rundlichen Koprolithen mit einem Durchmesser von 25-40 $\mu \mathrm{m}$.

In dem bereits durch Trametites teilweise stark zerstörten Holz (Lesbos 164) mit PiceoxylonStruktur (siehe S. 61) waren außer der Weißlochfäule auch Käferlarven mit einem Fraßbild ganz anderer Dimension an der Zerstörung des Holzes beteiligt. Auf dem Quer- und Radialschliffen sind schräg angeschnittene Fraßgänge mit einem Durchmesser von 1,9-2,2 mm vorhanden (Taf. 1: 7, Taf. 2: 5). Die Fraßgänge sind mit zahlreichen großen, häckselartig im Gang liegenden Fraßrückständen und mehr oder weniger ,wolkig“ verteilten Koprolithen ausgefüllt. Nur gelegentlich liegen kompakte, walzenförmige bis langelliptische Koprolithen mit einem Durchmesser bis $250 \mu \mathrm{m}$ und einer Länge bis $440 \mu \mathrm{m}$ im Gang. Die Fraßrückstände setzen sich häufig aus Gewebekomplexen zusammen, die aus drei bis vier nebeneinander liegenden und bis mehr als $500 \mu \mathrm{m}$ langen Tracheiden- und Holzstrahlresten bestehen. Nach den bis 2,2 mm im Durchmesser großen Fraßgängen zu urteilen, kommen nach Vité (1953: 53 ff) zwar auch nur kleinere Käferarten als Holzzerstörer infrage, die sich aber von den vorher beschriebenen deutlich durch die bedeutend größeren Durchmesser ihrer Fraßgänge und den großen groben Fraßrückständen unterscheiden.

Ein weder durch Pflanzen noch durch Tiere verursachtes Schadbild konnten wir in einem Nadelholzrest (Lesbos 168) mit vermutlicher Pinoxylon-Struktur nachweisen. Auf allen drei Schnittebenen befanden sich kleine, schrotschussartig verteilte, runde bis ovale, vermeintliche "Bohrlöcher" mit einem Durchmesser bis $160 \mu \mathrm{m}$ (Taf. 2: 8). Es kann sich bei diesem Schadbild jedoch nur um kugelförmige Gebilde handeln, die in den Tracheidenhohlräumen durch Kristallisationsvorgänge entstanden sind. Häufig haben die während der Fossilisierung sich entwickelnden Kristalle die anliegenden Tracheidenwände nachträglich seitlich verdrängt, ein Schadbild, das ein im Holz fressender Schädling nicht hinterlässt.

\section{Schlussbemerkungen}

Das für diese Arbeit zur Verfügung stehende Untersuchungsmaterial stammt aus dem versteinerten Wald von Lesbos, der zum Zeitpunkt seiner totalen Vernichtung durch gewaltige Vulkanausbrüche nahezu das gesamte Gebiet des nordwestlichen Teils der Insel Lesbos bedeckte und sich aus einem mehrstufig, vertikal gegliederten Mischwald zusammensetzte. Der Mischwald bestand aus Ginkgogewächsen, Koniferen und Angiospermen, wobei die Koniferen Pinoxylon paradoxum Süss \& Velitzelos und Taxodioxylon albertense (Penhallow) Shimakura die dominierenden Vertreter dieses Waldes waren (Süss \& Velitzelos 2001).

Da mit der Vernichtung dieses Waldes gleichzeitig auch alles Leben der an, im und vom Holz lebenden Organismen ausgelöscht wurde, ergab sich die seltene Gelegenheit, gleichzeitig mit der Bearbeitung der Holzfossilien die an ihnen von holzzerstörenden Organismen hinterlassenen Schadbilder zu analysieren und bestimmten Le-

Tafel 3. Pinoxylon pseudoparadoxum Süss \& Velitzelos (Lesbos 169), 30:1. 1-3. Übersichtsbilder von Querschliffen zeigen mit Fraßrückständen und Koprolithen ausgefüllte Fraßgänge von Käferlarven. 4-8. Radialschliffe: 4. Große, langelliptisch bis walzenförmige Koprolithen einer Käferlarve. 5. Zu einem Platzfraß sich ausweitender Fraßgang einer Käferlarve mit großen Koprolithen und spanartigen Fraßrückständen. 6. Fraßgang einer Käferlarve im Spätholz mit kleinen Koprolithen. 7. Fraßgang einer Käferlarve im Frühholzbereich mit mittelgroßen Koprolithen und spanförmigen Fraßrückständen. 8. Fraßgang einer Käferlarve im Spätholzbereich mit kleinen Koprolithen.

Plate 3. Pinoxvlon pseudoparadoxum Süss \& Velitzelos (Lesbos 169), 30:1. 1-3. Outline figure of transverse sections, showing feeding channels of beetle larvae, filled with feeding remains and coprolites. 4-8. Radial sections: 4. Large, elongate-elliptical to cylindrical coprolites of a beetle larva. 5. Feeding location of a beetle larva with large coprolites and chiplike feeding remains. 6. Feeding trace with small coprolites of a beetle larva in latewood. 7. Feeding trace with medium-sized chiplike feeding remains of a beetle larva in early wood. 8. Feeding trace with small coprolites of a beetle larva in latewood. 
bewesen zuzucrdnen. Die Untersuchungen ergaben, dass die durch ihre Lebensspuren nachgewiesenen Holz schädlinge in zwei Gruppen eingeteilt werden kinnen:

1. Schädlinge, die parasitisch am und im lebenden Holz le sen und

2. Schädlinge, die saprophytisch das bereits abgestorbene Holz befallen.

Zur ersten Gruppe gehören die Pflanzensauger. die Kambium-Minierfliegen und die TrametitesPilze. Die Pflinzensauger aus der Familie der Margarodidae und die Larven der Kambium-Minierfliegen aus der Dipteren-Familie Agromyzidae befallen cien Stamm, ohne das Leben des Baumes zu berlrohen. Die Trametites-Pilze dagegen, im rezenten Holz als Weißlochfäule und Weißfäulepilze bekannt, sind gefährliche Holzzerstörer, die den Baum zum Absterben bringen können.

Zur zweiten Gruppe gehören Bakterien und Pilze sowie tierische Organismen. Die Bakterien können nur ze lulosefreie, parenchymatische Zellen befallen. Pilze konnten vor allem durch ihre Abbauprodukte nachgewiesen werden, vergleichbar mit den :Zersetzungserscheinungen. die rezente Braunfäulepilze wie der Echte Hausschwamm, der Kellerschwamm und der Weiße Porenschwamm hinterlassen. Von den tierischen Organismen, die das Holz abgestorbener Baumstämme besielleln, konnte Termitenbefall und von Coleopteren-Arten verursachter Käferfraß nachgewiesen 'werden.

Die Unters uchungen zeigen, dass zwischen den Zerstörungsbildern der fossilen und rezenten Hölzer $w$ aitgehende Übereinstimmung besteht, denn die an den fossilen Hölzern gefundenen Bilder del Schadorganismen sind denen der im Holz heuticer Bäume vorkommenden im Wesentlichen gleic $h$.

Die Stücke und Schliffpräparate zu den Figuren der Tafeln 1 bis 3 Lesbos 118. 141, 145 und 162-169 werden in der Sammlung Lesbos. Department of Historical Geology and Paleontology, National University of Athens, aufbewahrt. Der Holzrest von Abbildung 1 befindet sich in der Sammlun des Naturhistorischen Museums „Petrified For sst of Lesbos" auf der Insel Lesbos, Griechenlınd.

\section{Danksagung}

Für die großzügig:? Unterstützung bei der Durchführung der Geländearbeiten tedanken wir uns bei dem Agäis-Ministerium von Griechen and. Sehr herzlich bedanken wir uns für fachliche Ausküntte bei Herrn Dr. G. Schultze-Dewitz (Eberswalde) und für die Linterstützung bei fototechnischen
Arbeiten bei Frau W. Harre (Berlin). Für die Hilfe bei der Beschaffung schwer zugänglicher Literatur sind wir Herrn K.-E. Balzer (Darmstadt) und Herrn Prof. Dr. A. Selmeier (München) zu Dank verpflichtet.

\section{Literatur}

Abel. O. 1933. Ein fossiles Termitennest aus dem Unterpliozän des Wiener Beckens. - Verhandlungen der zoologisch-botanischen Gesellschaft in Wien 83: 38-39.

Abel. O. 1935. Vorzeitliche Lebensspuren. - 644 S., G. Fischer. Jena.

Andrews. H. N. Jr. 1961. Studies in paleobotany. - 487 S., Wiley. New York, London.

Becker. G. 1949. Bestimmung von Insektenfraßschäden an Nadelholz. - Zeitschrift für angewandte Entomologie 32: $275-303$

Břczinová. D. \& Süss, H. 1987. Untersuchungen über Fossilisationsprozesse an verkicselten Pflanzenresten der miozänen Hornsteine von Lipnice (CSSR). - Zeitschrift für geologische Wissenschaften 15: 733-738.

- 1988. Nadel- und Laubholgreste aus miozänen Hornsteinen von Lipnice. CSSR. - Feddes Repertorium 99 $279-289$

Brues, C. T. 1936. Evidence for insect activity prescrved in fossil wood. - Journal of Paleontology 10: 637-643.

Buchholz. H. 1986. Die Höhle eines Spechtvogels aus dem Eozän von Arizona. - Verhandlungen des naturwissenschaftlichen Vereins in Hamburg (N.F.) 28: 5-25.

Conwentz. H. 1890. Monographie der baltischen Bernsteinbäume. Verglcichende Untersuchungen über die Vegetationsorgane und Blüten, sowie über das Harz und die Krankheiten der baltischen Bernsteinbäume. - 151 S., Wilhelm Engelmann, Danzig.

Daber. R. 1953. Betrachtung über Markasitisierung eines Koniferenholzes aus dem Miozän der Tongrube Guttau, Kreis Bautzen. - Geologie 2: 263-265.

Felix. J. 1894. Studien über fossile Pilze. - Zeitschrift der deutschen geologischen Gesellschaft 46: 269-280.

Geinitz. H. B. 1855. Die Versteinerungen der Steinkohlenfor mation in Sachsen. - 61 S. Wilhelm Engelmann, Leipzig.

Gellhorn. O. v. 1893. Insektenfraß in der Braunkohle der Mark Brandenburg. - Jahrbuch der königlich preußischen geologischen Landesanstalt für 1893: 49-53.

Goth. K. \& Wilde. V. 1992. Fraßspuren in permischen Hölzern aus der Wetterau. - Senckenbergiana lethaea $\mathbf{7 2}$ : $1-6$.

Grosser. G. 1985. Pflanzliche und tierische Bau- und Werkholzschädlinge. - 159 S., DRW-Verlag Weinbrenner-KG, Leinfelden-Echterdingen.

Jurasky. K. A. 1932. Fraßgänge und Koprolithen eines Nagekäfers in liassischer Steinkohle. - Zeitschrift der deutschen geologischen Gesellschaft 84: 656-657.

Kolbc. H. J. 1888. Zur Kenntnis von Insektengängen in fossilen Hölzern. - Zeitschrift der deutschen geologischen Gesellschaft 40: 131-137.

Linck. O. 1949. Fossile Bohrgänge an einem Keuperholz. Neues Jahrbuch für Mineralogie. Geologie und Paläontologie (B) 1949: 180-185.

Liphschitz. N. \& Mendel, Z. 1987. Histological studies of Pinus halepensis stem xylem affected by Matsucoccus josephi (Homoptera: Margarodidae). - AWA Bulletin, n. s. 8: $369-376$

Luxton. M. 1972. Studies on the oribatid mites of a Danish beech wood soil. - Pedobiologia 12: 434-463.

Müller-Stoll. W. R. 1936. Pilzzerstörungen an einem jurassischen Koniferenholz. - Palaeontologische Zcitschrift 18: $201-212$.

- 1951. Mikroskopic des zersetzten und fossilisicrten Holzes. In Freund. H. (ed.). Handbuch der Mikroskopie in der Technik, Bd. V (2): 725-816, Umschau Verlag, Frankfurt am Main. 
- 1989. Fraßgänge und Koprolithen eines holzbewohnenden Käfers miozänen Alters aus dem Lettengraben (Herrenwasser) in der Rhön. - Archäopteryx 7: 51-57.

Müller-Stoll, W. R. \& Mädel, E. 1957. Über tertiäre Eichenhölzer aus dem pannonischen Becken. - Senckenbergiana lethaea 38: $121-168$

Rammer, W. 1952. Brehms Tierleben. Erster Band: Wirbel lose (2. Aufl.) - 464 S., VEB Bibliographisches Institut, Leipzig.

Schenk, E. 1937. Insektenfraßgänge oder Bohrlöcher von Pholadiden in Ligniten aus dem Braunkohlenflöz bei Köln. - Neues Jahrbuch für Mineralogie, Geologie und Paläontologie 77, Abt. B: 392-401.

Schmidt, O. 1980. Über den bakteriellen Abbau der chemisch behandelten verholzten Zellwand. - Material und Organismen 15: 207-224.

Schönfeld. E. 1955. Die Kieselhölzer aus der Braunkohle von Böhlen bei Leipzig. - Palaeontographica 99 B: 1-83.

- 1957. Ein pilzkranker Stamm von Cupressinoxylon cupressoides Kräusel aus der hessischen Braunkohle. - Senckenbergiana lethaea 38: 109-119.

Schönfeld, G. 1947. Hölzer aus dem Tertiär von Kolumbien. - Abhandlungen der Senckenbergischen Naturforschenden Gesellschaft 475: $1-53$.

Schultze-Dewitz, G. \& Süss, H. 1988: Fossiler Termitenfraß an Holzresten aus dem Tertiär von Staré Sedlo (CSSR). Ein Beitrag zu den Termiten der Vorwelt. - Zeitschrift für geologische Wissenschaften 16: 169-173.

Scott, A. \& Taylor, T. N. 1983: Plant/animal interactions during the Upper Carboniferous. - The Botanical Review 49: $259-307$.

Selmeier, A. 1984. Fossile Bohrgänge von Anobium sp. in einem jungtertiären Lorbeerholz aus Egweil (südliche Frankenalb). - Archäopteryx 1984: 13-29.

- 1996. Ein verkieseltes Gymnospermenholz mit Fraßgängen von Teredo aus La Calamine (Belgien). - Mitteilungen der Bayerischen Staatssammlung für Paläontologie und historische Geologie 36: 185-196.

Spencer, K. 1990. Host spccialisation in the world Agromyzidae (Diptera). - 444 S., Kluwer Academic Publication, Dordrecht, Boston, London.

Stubblefield, S. P. \& Taylor, T. N. 1986. Wood decay in silified gymnosperms from Antartica. - Botanical Gazette 147: $116-125$.

Süss. H. 1979. Durch Protophytobia cupressorum gen. nov. sp. nov. (Agromyzidae, Diptera) verursachte Markflecke in einem Holz von Juniperoxylon aus dem Tertiär von Süd-Limburg (Niederlande) und der Nachweis von Markflecken in einer rezenten Callitris-Art. - Feddes Repertorium 90: $165-172$

- 1980a. Ein Platanenholz aus dem Untereozän der Greifswalder Oie, Platanoxylon coheni (Schuster) comb. nov. Schriftenreihe für geologische Wissenschaften $\mathbf{1 6}$ : $401-416$.
- 1980b. Fossile Kambium-Minierer der Familie Agromyzidae (Diptera) in tertiären Laub- und Nadelholzresten. - Zeitschrift für geologische Wissenschaften $\mathbf{8}$ $1217-1225$

- 1982. Die Holzanatomie als Hilfswissenschaft der Entomologie. - Gleditschia 9: 27-31.

- 1997. Tetraclinoxylon velitzelosi sp. nova, ein neues fossiles Holz aus tertiären Schichten des Versteinerten Waldes von Lesbos, Griechenland. - Feddes Repertorium 108: 289-298.

Süss, H. \& Müller-Stoll, W. R. 1975. Durch Palaeophytobia platani n.g., n.sp. (Agromyzidae, Diptera) verursachte Markflecken im Holz fossiler Platanen aus dem ungarischen Miozän. - Wissenschaftliche Zeitschrift der Humboldt-Universität zu Berlin, mathematisch-naturwissenschaftliche Reihe 24: 515-519.

- 1980. Das fossile Holz Pruninium gummonim Platen emend. Süss et Müller-Stoll aus dem Yellowstone Nationalpark und sein Parasit Palaeophytobia prunorum sp. nov. nebst Bemerkungen über Markflecke. In Vent. W (Hrsg.). 100 Jahre Arboretum Berlin (1879-1979): 343-364. Akademie-Verlag, Berlin.

Süss, H. \& Philippe, M. 1993. Holzanatomische Untersuchungen an einem fossilen Holz. Circoporoxylon grandiporosum Müller-Stoll et Schultze-Motel, aus dem Unteren Jura von Frankreich. - Feddes Repertorium 104: 451-463.

Süss, H. \& Rangnow, P. 1984. Die Fossiliensammlung Hcinrich Cottas im Museum für Naturkunde der HumboldtUniversität zu Berlin. - Neue Museumskunde 27: 17-30.

Süss, H. \& Velitzelos, E. 1997. Fossile Hölzer der Familie Taxodiaceae aus tertiären Schichten des Versteinerten Waldes von Lesbos. Griechenland. - Feddes Repertorium 108: 1 - - 30

- 2001. Chimairoidoxylon conspicuum sp. nova, ein neues fossiles Holz der Formgattung Chimairoidoxylon Süss \& Velitzelos emend. Süss, mit einer Übersicht über das Vorkommen fossiler Hölzer auf der Insel Lesbos. Griechenland. - Feddes Repertorium 112: 149-157.

Taylor, T. N. \& Osborn, J. M. 1992. The role of wood in understanding saprophytism in the fossil record. - Courier Forschungsinstitut Senckenberg 147: 147-153.

Tufar, W. 1968. Pyritisierte Hölzer eozänen Alters aus OstHolstein. - Meyniana 18: 65-78.

Vité, J. P. 1953. Die holzzerstōrenden Insekten Mitteleuropas Tafelband. 78 S. „Musterschmidt”. Wissenschaftlicher Verlag, Göttingen.

Zhou Zhiyan \& Zhang Bole. 1989. A sideritic Protocupressinoxylon with insect borings and frass from the middle Jurassia, Henan. - Review of Palaeobotany and Palynology 59: $133-143$.

Zwenger, W. H. 1987. Zu einigen besonderen Erhaltungsformen tertiärer Bohrmuschelspuren. - Hercynia (N.F.) 24 $249-255$. 